\title{
Preparation of Basalt Incorporated Polyethylene Composite with Enhanced Mechanical Properties for Various Applications
}

\author{
Pavel Bredikhin ${ }^{1}$, Yulia Kadykova ${ }^{2}$, Igor Burmistrov ${ }^{1}$, Tamara Yudintseva, ${ }^{2,}$, Igor Ilinykh $^{2}$, Aleksandr Kupava $^{2}$ \\ ${ }^{1}$ Yuri Gagarin Saratov State Technical University, Saratov, Russia \\ ${ }^{2}$ National University of Science and Technology MIS\&S, Moscow, Russia
}

\begin{abstract}
The present article showed the possibility of increasing the complex of mechanical properties of polyolefins with dispersed mineral fillers obtained by fine grinding of basalt rocks via ball mill processing. The composites based on dispersed basalt, which were derived from Samara rock mass (Russia) with rare earth elements containing, were obtained by extrusion combining the binder and filler, followed by preparation injection-molded test samples. The study of mechanical properties of materials developed showed the possibility of a significant increase in strength characteristics of different types of polyethylene: the breaking stress at static bending for HDPE can be increasing more than $60 \%$ and the impact strength by more than 4 times. In addition the incorporation of the dispersed basalt also enhanced the thermal properties of the composites (the oxygen index of HDPE increases from 19 to $25 \%$ ).
\end{abstract}

\section{Introduction}

During the processing of basalt rock, including the allocation of rare earths elements, may be formed the basalt powder waste. In this paper, one of the possible technologies of it secondary application was considered. Powdered and stone waste of ores processing containing rare earth can be used as additives in polymeric materials. Therefore in this article we have considered aspects of their influence on the mechanical properties of polymer matrix composites based on one of the most large-materials polyethylene.

Polyolefins are generally the most commonly produced polymers, the amount of its production is more than tens of millions tons $35 \%$ of the world production of polymers) [1]. The most important representative of this class of polymers is polyethylene (PE).

PE is widely used due to its excellent properties such as: sufficiently high strength, resistance to corrosion, radiation, non-toxic and high dielectric properties [2]. However, the main disadvantage of PE is low modulus of elasticity and deformation under load, which limits its use. In addition, the incorporation of PE in various fillers significantly improves a complex of its physical and mechanical properties [2]. Moreover, the current economic climate requires not only the production of composites with a high characteristic complex, but also with a sufficiently low cost. In these reason various types of mineral fillers have become widespread: kaolin, talc, mica, chalk, silica, aerosil, titanium oxide, aluminum oxide, etc. [3-5]. Thus, most effective approach, to improve characteristics composite materials are incorporated in the use of inexpensive and efficient fillers, which include basalt and its derivatives thereof. Basalt is non-flammable, high temperatures resistant $\left(900^{\circ} \mathrm{C}\right)$, durable, resistant to mechanical stress, has high sound and heat insulating properties, biological stability, chemically non-reactive and non-radiation. The basalts are ecofriendly materials and non-toxic to humans and animals [6-7]. Due to these unique properties the basalt can be applied in various fields of engineering and technology. In the field of modification of polymer materials are used only basalt fiber and their derivatives. Moreover milled basalt as a dispersed filler has not been previously investigated. The aim of this work is to analyze the possibility of creating polymer composite materials based on polyethylene and dispersed basalt. In addition, study their physicalmechanical and chemical properties, due to the incorporation of polyethylene and dispersed basalt.

\section{Materials and methods}

As a binder low-density polyethylene (LDPE) and high-density polyethylene (HDPE) were used.

Corresponding author: yudintsevatoma@gmail.com 
Table 1. The chemical composition of the basalt.

\begin{tabular}{|c|c|}
\hline Component & Content, wt\% \\
\hline Sodium oxide $\mathrm{Na}_{2} \mathrm{O}$ & 2.78 \\
\hline Potassium oxide $\mathrm{K}_{2} \mathrm{O}$ & 0.67 \\
\hline Calcium oxide $\mathrm{CaO}$ & 9.35 \\
\hline Magnesium oxide $\mathrm{MgO}$ & 15.86 \\
\hline Phosphorus oxide $\mathrm{P}_{2} \mathrm{O}_{5}$ & 0.5 \\
\hline Iron oxide $\mathrm{Fe}_{2} \mathrm{O}_{3}$ & 9.57 \\
\hline Silicon oxide $\mathrm{SiO}_{2}$ & 49.88 \\
\hline Aluminum oxide $\mathrm{Al}_{2} \mathrm{O}_{3}$ & 10.09 \\
\hline Titanium dioxide $\mathrm{TiO}_{2}$ & 1.08 \\
\hline Manganese oxide $\mathrm{MnO}$ & 0.22 \\
\hline Loss on ignition & 2.92 \\
\hline
\end{tabular}

Derived from Samara rock mass basalt with rare earth elements containing (chemical composition thereof shown in Table 1 and Table 2) were used as a filter, in the present investigation.

Table 2. Content of rare earth and trace elements in the basalt.

\begin{tabular}{|c|c|}
\hline Rare earth and trace elements & Content, g/tonne \\
\hline $\mathrm{Cr}$ & 780 \\
\hline $\mathrm{Ni}$ & 630 \\
\hline $\mathrm{Co}$ & 83 \\
\hline $\mathrm{La}$ & 33.2 \\
\hline $\mathrm{Ce}$ & 68.8 \\
\hline $\mathrm{Pr}$ & 8.1 \\
\hline $\mathrm{Nd}$ & 34.5 \\
\hline $\mathrm{Sm}$ & 9.37 \\
\hline $\mathrm{Eu}$ & 3.42 \\
\hline $\mathrm{Gd}$ & 11.2 \\
\hline $\mathrm{Tb}$ & 1.72 \\
\hline $\mathrm{Dy}$ & 9.5 \\
\hline $\mathrm{Ho}$ & 2.01 \\
\hline $\mathrm{Er}$ & 5.5 \\
\hline $\mathrm{Tm}$ & 0.77 \\
\hline $\mathrm{Yb}$ & 4.22 \\
\hline $\mathrm{Lu}$ & 0.64 \\
\hline & \\
\hline & \\
\hline
\end{tabular}

Preparation of PE incorporated basalt composite: the basalt crushed in a ball mill 62ML-A (MechanobrTekhnika, St. Petersbuig, Russia) for 15, 30 and 60 minutes at $50 \mathrm{rev} / \mathrm{min}$. The ratio of the ground material weight to the grinding weight is $1: 8$. After grinding the unground particles product was sieved through $0.140 \mathrm{~mm}$ diameter. Shapes and sizes of the fillers, as well as the structure of the composites were analyzed using scanning electron microscope (SEM) Vega 3SB (Tescan, Czech Republic), at an accelerating voltage of $7 \mathrm{kV}$.

The composites were prepared by dispersing basalt in PE by using extruder granulator EPK $25 \times 30$ (Polyprom Kuznetsk, Russia). Test specimens were produced on an injection molding machine Haitian SA 900 (Haitian Plastics Machinery, China).

Melt flow index testing according to the ISO 1133 was made using Aflow Extrusion Plastometer 032295 (Zwick Roell, USA). Test conditions for HDPE: temperature $-(190 \pm 0,5){ }^{\circ} \mathrm{C}$, load - $5 \mathrm{~kg}$. Test conditions for LDPE: temperature $-(190 \pm 0.5){ }^{\circ} \mathrm{C}$, load $-2.16 \mathrm{~kg}$.
Breaking bending stress was determined according to ISO 178:2010; tensile stress at break and elongation at break were determined in accordance with ISO 527-1. Tests were carried out on a tensile testing machine INSTRON 5569 (Instron, USA). Brinell hardness was determined in accordance with ISO 2039/1-87 using HBE-3000A electronic Brinell Hardness Tester (Beijing United Test Co., Ltd., China). The impact strength was determined according to ISO 179-82 using a plastic tensile impact testing machine LCT - 50D (Beijing United Test Co., Ltd., China). The details of calculating of the test results are presented in section "Nomenclature list".

The composite materials were tested for flammability through oxygen index (EN ISO 4589-2).

\subsection{Nomenclature list}

Bending stress measurements:

$$
\sigma_{s b}=\frac{3}{2} \frac{P^{*} d}{b^{*} h^{2}}
$$

$\sigma_{\mathrm{sb}}-$ breaking stress at static bending, Pa; P breaking load in static bending, $\mathrm{N}$ (it was measured with a tensile testing machine INSTRON 5569 according to ISO 178:2010); $\mathrm{d}$ - span, $\mathrm{m}$ (set $64 \mathrm{~mm}$, according to ISO 178:2010); b - width of the sample, $\mathrm{m} ; \mathrm{h}$ - thickness of the sample, $\mathrm{m}$ (it was set recommended type of sample according to ISO $178: 2010$ with $b=10.0 \pm 0.2 \mathrm{~mm}, \mathrm{~h}=4.0 \pm 0.2 \mathrm{~mm}$ ).

Impact strength measurements:

$$
a_{i}=\frac{P_{i}}{b^{*} h}
$$

$a_{i}$ - impact strength, $\mathrm{J} / \mathrm{m}^{2} ; \mathrm{P}_{\mathrm{i}}-$ impact energy, $\mathrm{J}$ (it was measured with a plastic tensile impact testing machine LCT - 50D according to ISO 179-82; sample size: $\mathrm{l}=80.0 \pm 0.2 \mathrm{~mm}, \mathrm{~b}=10.0 \pm 0.2 \mathrm{~mm}, \mathrm{~h}=4.0 \pm 0.2$ $\mathrm{mm})$.

Tensile stress measurements:

$$
\begin{aligned}
\sigma_{b} & =\frac{F}{b^{*} h} ; \\
\varepsilon_{b} & =\frac{F}{b^{*} h} * 100 \%
\end{aligned}
$$

$\sigma_{\mathrm{b}}-$ tensile stress at break, $\mathrm{Pa} ; \varepsilon_{\mathrm{b}}-$ elongation at break, \%; $\mathrm{F}$ - tensile breaking load, $\mathrm{N}$ (it was measured with a tensile testing machine INSTRON 5569 according to ISO 527-1.)

Brinnel hardness measurements:

$$
H_{b}=\frac{2 * 1839}{\pi * D^{*}\left(D-\sqrt{D^{2}-d^{2}}\right)}
$$

$\mathrm{H}_{\mathrm{b}}$ - Brinnel hardness, MPa; D - indenter diameter, $\mathrm{m}$ (it was measured with a electronic Brinell Hardness Tester HBE-3000A according to ISO 2039/1-87).

\section{Results and discussion}

The microscopic image observed through SEM of dispersed basalt is shown in Figure 1. The result 
reveals that the particles are in irregular shape and size according to the milling time.

When the grinding is performed for 15 minutes the composition of the dispersed basalt predominantly presents the particles larger than 10 microns, with the number of smaller particles (Fig. 1). When grinding is carried for 30 minutes the formation of smaller sized particles around 3-6 microns were obtained. However, longer grinding for 60 minutes represents the formation of a large number of particles with sizes less than 1 micron, but the obtained powder included the particles with size about 5 microns and the aggregates of larger than 10 microns. Hereafter the obtained powders of the dispersed basalt are designated as follows: basalt after grinding for 15 minutes - DB15; basalt after grinding for 30 minutes DB30; basalt after grinding for 60 minutes - DB60 (Fig. 1).

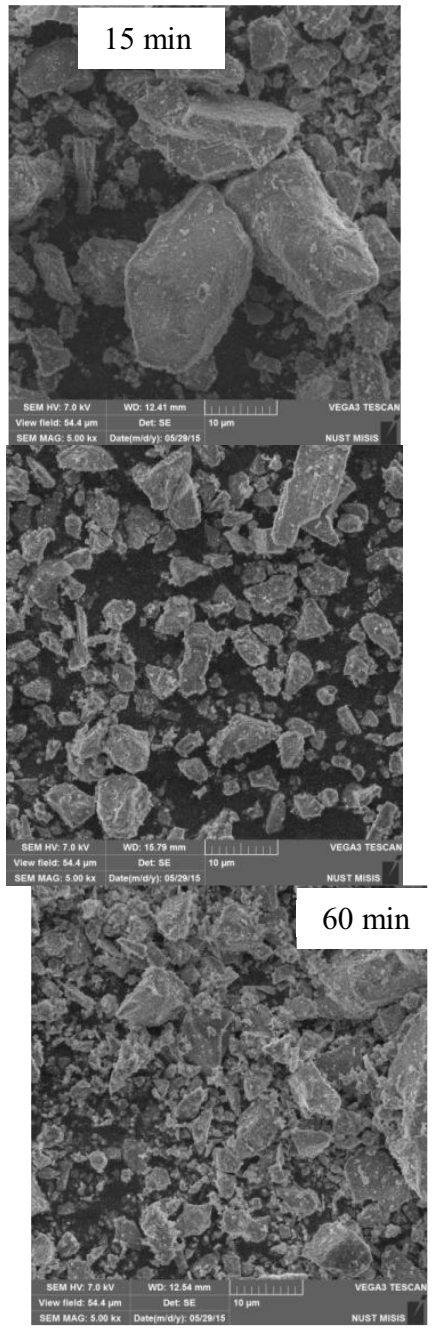

$30 \min$

Fig. 1. Dependence particle size and shape of the dispersed basalt on grinding time with a planetary mill.

Evaluation of the rheological properties of the filled composites (Table 3) showed that with the increase in content of the basalt, the fluidity of the compositions decreased gradually when compared to unfilled systems. However, the obtained compositions have the melt flow rate big enough (more than $5 \mathrm{~g} /$ $10 \mathrm{~min}$ ) for processing by the injection molding.

Table 3. Changing the melt flow index of the composition.

\begin{tabular}{|l|c|}
\hline $\begin{array}{c}\text { The composition, wt\% per 100 } \\
\text { wt\% PE }\end{array}$ & $\begin{array}{c}\text { Melt flow index, } \\
\text { g/10 } \text { min }\end{array}$ \\
\hline HDPE & 23 \\
\hline HDPE+30 DB30 & 18 \\
\hline HDPE+40 DB30 & 16 \\
\hline HDPE+50 DB30 & 15 \\
\hline LDPE & 5.5 \\
\hline LDPE+30 DB30 & 5.2 \\
\hline LDPE+40 DB30 & 5.1 \\
\hline LDPE+50 DB30 & 5.0 \\
\hline
\end{tabular}

Study of physical and mechanical properties of developed polymer composite materials (PCM) showed that with the addition of the dispersed basalt there is an increase in resistance to static bending and impact loads (Figures 2-5). As demonstrated in figures, the best results achieved with the addition of $40 \mathrm{wt} \%$ of dispersed basalt. The extreme behaviour is typical for the strength properties dependency of the dispersed filler content in the polymer composite. This concentration dependence keeps for all particle sizes: DB15, DB30 and DB60.

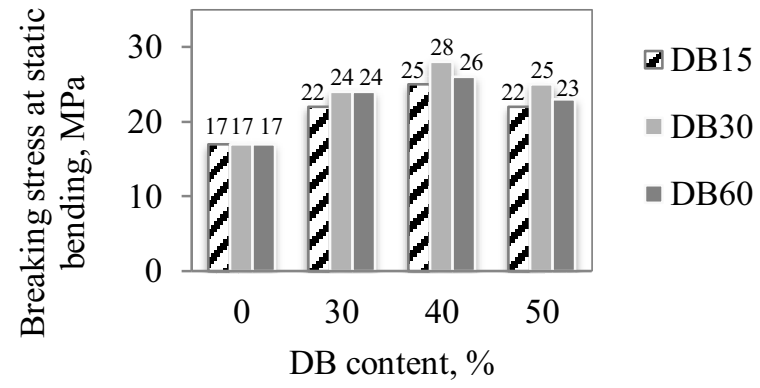

Fig. 2. Effect of content and particle size of the dispersed basalt on breaking stress at static bending HDPE.

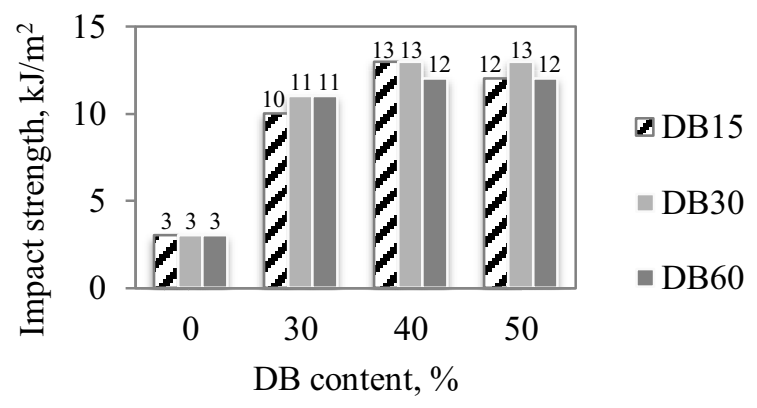

Fig. 3. Effect of content and particle size of the dispersed basalt on breaking stress at impact strength HDPE. 


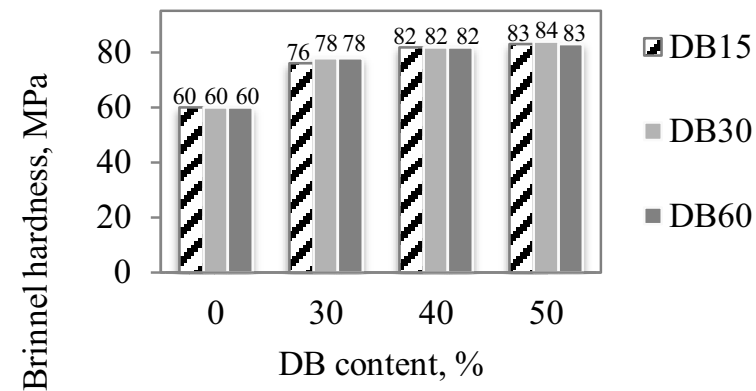

Fig. 4. Effect of content and particle size of the dispersed basalt on breaking stress at Brinnel hardness HDPE.

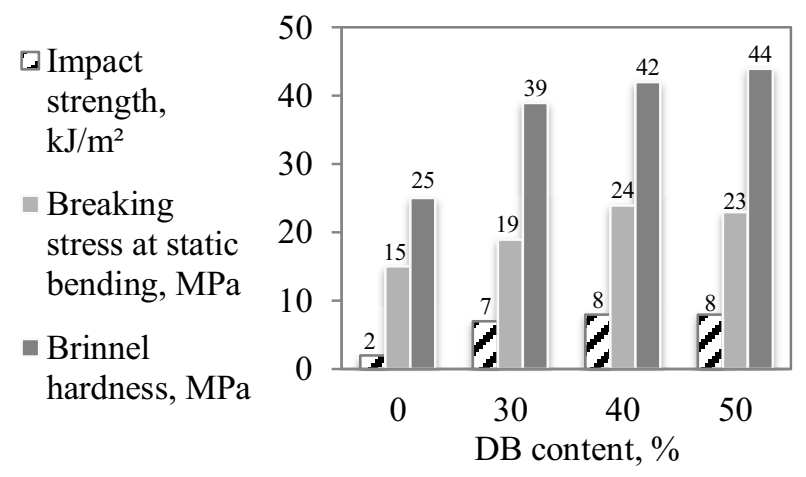

Fig. 5. Effect of dispersed basalt DB30 on the mechanical properties of LDPE $\mathrm{m}^{2}$

By compare the reinforcing effect of various particle sizes of dispersed basalt the most effective method was for DB30. This might be due to the finer particles in comparison with DB15, higher homogeneous particle size distribution and the absence of aggregates in comparison to DB60.

It was found that the breaking stress at static bending for HDPE can be increasing more that $60 \%$ with incorporation $40 \mathrm{wt} \%$ of DB30 (Fig. 2). The impact strength for HDPE in this case can be increasing by more than 4 times (Fig. 3). This may be associated with significant energy losses in the dissemination of cracks in the highly filled polymer matrix.

It should be noted that the Brinell hardness insignificantly increasing (less 40\%) when dispersed basalt incorporated into HDPE (Fig. 4).

With the introduction DB30 into LDPE matrix a significant increase of Brinell hardness (over 76\%) was observed (Fig. 5). Other mechanical properties increase similarly to the HDPE (Fig. 5).

The addition of $40 \mathrm{wt} \%$ DB30 to the HDPE and LDPE the oxygen index increases from 19 to 25 and 24 vol \% respectively. Basalt content double reduces the self-combustion compared to the unfilled PE (Fig. 6 ), and also reduced weight loss when ignited in air. All flammability indexes additively vary with basalt content, which is non-combustible material.

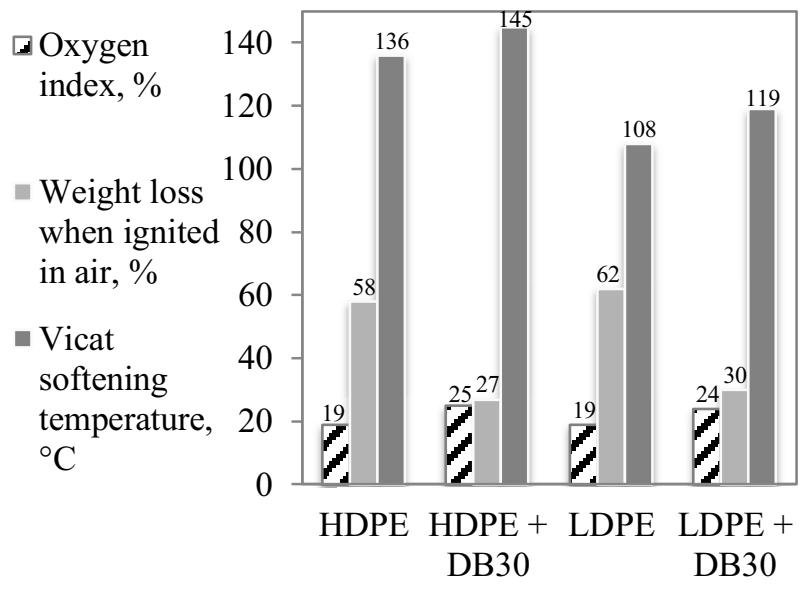

Fig. 6. Effect of DB30 on thermal resistance and combustibility of the filled polyethylene.

\section{Conclusion}

In this paper is shown the possibility of recycling of earth produce waste by introducing them into the polymer matrix composites. An important result shown in this study is the establishment of the possibility of increasing the strength characteristics of materials based on polyethylene with the addition of fine waste basalt products.

The efficiency of the use of dispersed basalt filling polyethylene was shown. The effect of dispersed basalt particle size on the indexes of physical and mechanical properties of HDPE and LDPE. Chosen optimal time of basalt grinding in a ball mill is analyzed to understand degree of fineness.

Enhanced physico-chemical and mechanical properties of the compositions filled with basalt, thus expanding the scope of basalt usage to create polymer composite materials for wide range of applications. In addition, the optimal content of dispersed basalt was found to be $40 \mathrm{wt} \%$. In these case the breaking stress at static bending for HDPE has been increasing more than $60 \%$ and the impact strength by more than 4 times.

The influence of the basalt additives on indexes of polyethylene polymer composite materials flammability: oxygen index was analysed (it was increases from 19 to $25 \%$ ) based on self-combustion time, weight loss when ignited.

Dispersed basalt is extremely cheap material (in particular, it may be used waste of stone wool or fibers production), thus it can provide a significant increase of the strength of HDPE or LDPE, which is of great technical and economic importance.

This research was supported by Russian Ministry of Education and Science in frames of grants ID RFMEFI57814X0084.

\section{References}

1. M. Rahman, C. S. Brazel, Prog. Polym. Sci. 29, 1233 (2004) 
2. S. Ronca, Chapter 10 - Polyethylene in Brydson's Plastics Materials (Eighth Edition) (Elsevier Inc., 2017) available at http://dx.doi.org/10.1016/B978-0-323-358248.00010-4

3. S. E. Artemenko, Yu. A. Kadykova, Fibre Chemistry 40, 37 (2008)

4. I. N. Burmistrov, N. V. Shatrova, A. S. Mostovoy, I. N. Mazov, D. V. Kuznetsov, L. G. Panova, A. V. Gorokhovsky, A. G. Yudin, Polym. Eng. Sci. 54, 2866 (2014)

5. D. S. Muratov, D. V. Kuznetsov, I. A. Ilinykh, I. N. Burmistrov, I. N. Mazov, Compos. Sci. Technol. 111, 40 (2015)

6. S. E. Artemenko, Yu. A. Kadykova, Fibre Chemistry 40, 490 (2008)

7. S. E. Artemenko, S. V. Arzamastsev, D. A. Shatunov, A. A. Vyazenkov, Fibre Chemistry 40, 499 (2008) 